\title{
Activation of the Toll-like receptor 2 signaling pathway inhibits the proliferation of HCC cells in vitro
}

\author{
YI CHEN $^{1,2}$, ZUXIONG HUANG $^{2,3}$, XUZHENG CHEN $^{4}$ and HANHUI YE ${ }^{2,5}$ \\ ${ }^{1}$ United Innovation of Mengchao Hepatobiliary Technology Key Laboratory of Fujian Province, \\ Mengchao Hepatobiliary Hospital of Fujian Medical University; ${ }^{2}$ The Liver Center of Fujian Province, \\ Fujian Medical University; ${ }^{3}$ Department of Hepatology, Mengchao Hepatobiliary Hospital of Fujian Medical University, \\ Fuzhou, Fujian 350025; ${ }^{4}$ Academy of Integrative Medicine, Fujian University of Traditional Chinese Medicine, \\ Fuzhou, Fujian 350108; ${ }^{5}$ Department of Infectious Diseases, Mengchao Hepatobiliary Hospital of \\ Fujian Medical University, Fuzhou, Fujian 350025, P.R. China
}

Received December 20,2018; Accepted August 7, 2019

DOI: $10.3892 / o r .2019 .7340$

\begin{abstract}
Toll-like receptor 2 (TLR2), is an important pattern recognition receptor which serves a role in chronic inflammation of the liver. However, the role of TLR2 in the progression of human hepatocellular carcinoma (HCC) remains unknown. The aim of the present study was to examine the effects of the activation of the TLR2 signaling pathway on biological functions, such as proliferation and apoptosis. TLR2 expression in HCC tissues was assayed by quantitative polymerase chain reaction, flow cytometry and western blotting. B76/Huh7 cells were transfected with overexpression plasmids, and cell proliferation was detected using a Cell Counting Kit-8 assay and the secreted cytokines in the supernatant of transfected cells were measured by ELISA. The findings revealed that TLR2 expression was increased in the peritumoral groups compared with inner-tumoral groups. Activation of the TLR2 signaling pathway through overexpression of pathway molecules inhibited the growth of B76/Huh7 cells and the secretion of interleukin- 6 and tumor necrosis factor- $\alpha$ were
\end{abstract}

Correspondence to: Mr. Hanhui Ye, Department of Infectious Diseases, Mengchao Hepatobiliary Hospital of Fujian Medical University, 312 Xihong Road, Fuzhou, Fujian 350025, P.R. China E-mail: yehanhui@163.com

Abbreviations: HCC, hepatocellular carcinoma; PRR, pattern recognition receptor; TLR2, Toll-like receptor 2; MyD88, myeloid differentiation factor 88; IRAK1, interleukin-1 receptor-associated kinase 1; TRAF6, tumor necrosis factor receptor-associated factor-6; ASK1, apoptosis signal regulating kinase 1; p38 MAPK, p38 mitogen-activated protein kinase; $\mathrm{NF}-\kappa \mathrm{B}$, nuclear factor- $\kappa \mathrm{B} ; \mathrm{CCK}-8$, Cell Counting Kit-8; LSECs, liver sinusoidal endothelial cells; IL-6, interleukin-6; IL-8, interleukin-8; TNF- $\alpha$, tumor necrosis factor- $\alpha$; IFN- $\beta$, interferon- $\beta$; FCM, flow cytometry; Pam3CSK4, TLR1/2 agonist; DEN, diethylnitrosamine

Key words: TLR2 signaling pathway, MyD88, NF-кB, cytokines, proliferation reduced. Inhibition of the TLR2 signaling pathway resulted in a significant increase in the downstream signaling cascade, thus potentially increasing hepatocarcinogenesis and tumor progression. Activation of the TLR2 signaling pathway may be a potential target for therapeutic intervention in patients with HCC and downstream secreted cytokines are required for the functional biological effect. Therefore, modulation of the TLR2 signaling pathway may provide important insight into designing effective therapeutic regimens for treating patients with HCC.

\section{Introduction}

Hepatocellular carcinoma (HCC) is the fifth most common cancer in the world and the third leading cause of cancer-associated deaths in China $(1,2)$. The pathogenesis of HCC is closely associated with chronic inflammation, including inflammation initiated by contamination with bacteria, chemical materials and oxidation or metabolic stress. The liver is the organ where foreign antigens from the gastrointestinal tract encounter the immune system (3). The immune defense of the liver primarily depends on natural immunity.

The liver develops a variety of mechanisms against liver cancer gene mutations which result from foreign antigens (4). Toll-like receptors (TLRs) are important pattern recognition receptors required to maintain the balance of inflammatory and fibrogenic signaling in the liver. Stimulation of TLRs to activate the innate immune system has been a valid therapeutic strategy for treating patients with HCC for a number of years (5). TLR2 is one of the most well-studied TLRs and recognizes a variety of pathogens and damage-associated molecules, including myeloid differentiation factor 88 (MyD88) and the apoptosis signal regulating kinase 1 (ASK1)/p38 mitogen-activated protein kinase (p38 MAPK)/nuclear factor $\kappa \mathrm{B}(\mathrm{NF}-\kappa \mathrm{B})$ signaling pathway (6). Systemic targeting of TLR2 was demonstrated to be an efficacious option for treating $\mathrm{HCC}$ in mice (7). TLR2-deficient mice present a significantly increased rate of HCC carcinogenesis and progression. Animal data have shown that a new class of modified TLR2 agonists which were used for the pretreatment of liver sinusoidal endothelial 
cells (LSECs) can be administered systemically as a potential therapeutic intervention for improving liver cell immunity (8).

A number of studies have demonstrated that aberrant overexpression of TLR2 is present in liver samples of patients with different stages of liver disease (9), that TLR2 affects the bioactivity of HepG2 and BEL-7402 cell lines (10), and that Tlr2-null mice exhibit increased aggressive HCC development (11).

However, the mechanism through which TLR2 activation underlies tumor proliferation remains unknown. Confusingly, it has been reported that the role of TLR2 differs significantly between tumor tissues of the liver and peritumoral tissues (9). TLR2 in normal tissues directly attacks tumor cells, and additionally performs other indirect guard-like functions such as promoting the secretion of a number of cytokines. In contrast, TLR2 expression in the tumor site is considerably lower, and thus it may be used as an indicator for immune escape of tumor cells (11).

In the present study, TLR2 expression was found to be increased in liver carcinoma tissues at both the gene and protein levels, and the expression and downstream factors of TLR2 signaling were determined in B76/Huh7 cells cultured in the serum of HCC patients after stimulation of Pam3CSK4, a potent activator of the proinflammatory transcription factor $\mathrm{NF}-\kappa \mathrm{B} 1$ in vitro. The B76/Huh7 cells were treated with a variety of activating or inhibitory stimuli. The GFP-expressing plasmid pcDH-TLR2-GFP-PMV and pcDNA-MYD88-GFP were transfected into B76/Huh7 cells to determine the effects on HCC progression. The downstream endogenous cytokines interleukin (IL)-6, IL-8, tumor necrosis factor- $\alpha$ (TNF- $\alpha$ ), and interferon- $\beta$ (IFN- $\beta$ ), which ultimately converge on the NF- $\kappa B$ signaling pathway, were auxiliary factors. Overexpression of either TLR2 or MyD88 with Pam3CSK4 stimulation in B76/Huh7 cells decreased the growth of cells by inhibiting the activation of the downstream pathway. Transfection with siRNAs targeting TLR 2 or MyD88 significantly increased the downstream signaling cascade, which exacerbated the progression of hepatocarcinogenesis. Expression of the downstream cytokines IL-6, IL-8, TNF- $\alpha$ and IFN- $\beta$ was altered correspondingly. The results of the present study demonstrate a novel TLR2 signaling pathway involved in proliferation in HCC. Additional research is required to further illustrate the function of TLR2 in HCC.

\section{Materials and methods}

Patients and specimens. To investigate the relationship between HCC and the signaling pathway molecules of TLR2, a total of 20 paired fresh liver carcinoma tissues and pericarcinoma tissues were collected from patients undergoing curative resection without consideration of recurrence and/or metastasis at the Mengchao Hepatobiliary Hospital of Fujian Medical University (Fujian, China) between June 2010 and July 2016. Clinical and pathological diagnosis of HCC met the criteria of The American Association for the Study of Liver Diseases (https://www.aasld.org). Tumor stage was determined according to Barcelona Clinic Liver Cancer (BCLC) staging classification (12). Primary HCC and matched peritumoral tissues were defined by pathological sampling specification; all tumor tissues excised by hepatectomy were trimmed by an experienced pathologist to remove as much normal liver tissue as possible. Generally the pericarcinoma tissues were located $2 \mathrm{~cm}$ beyond the cancer tissues. The final obtained tumor tissues had at least $80 \%$ HCC cells as confirmed by $\mathrm{H} \& \mathrm{E}$ staining. Subsequently, the specimens were dissected and then frozen in liquid nitrogen for DNA extraction and subsequent experiments. Serum from patients with HCC was additionally preserved prior to undergoing curative resection. Additionally, the serum of normal healthy individuals was obtained from donors. The serum samples were centrifuged for $5 \mathrm{~min}$ at $300 \mathrm{x}$ g at $4^{\circ} \mathrm{C}$ and were frozen at $-80^{\circ} \mathrm{C}$. The study was approved by the Ethics Committee of the Mengchao Hepatobiliary Hospital of Fujian Medical University (study license no. 2016-007-01). Informed consent was obtained from patients and health recruits.

Cell lines and cell culture. The human hepatocellular carcinoma cell line, B76/Huh7, was purchased from the American Type Culture Collection (ATCC; Manassas, VA, USA). The B76/Huh7 cells were cultured in DMEM medium (Hyclone; Thermo, Fisher Scientific, Inc., Waltham, MA, USA) with 10\% fetal bovine serum (Gibco; Thermo, Fisher Scientific, Inc.) in a humidified incubator with $5 \% \mathrm{CO}_{2}$ at $37^{\circ} \mathrm{C}$.

Flow cytometry (FCM) detection of TLR2 expression. To determine the association between HCC and TLR2 as well as TLR2 downstream factors, the HCC tumor and peritumoral tissues were dissociated and $2 \times 10^{6}$ cells were analyzed by FACS Verse (FCM; BD Biosciences, San Jose, CA, USA). FlowJo 7.6.1(BD Biosciences, San Jose, CA, USA) was used for flow cytometric analysis (Engine 2.79000OS version: Windows 7 Java Version: 14.1-b02). Suspensions of $2 \times 10^{6}$ B76/Huh7 cells cultured in DMEM, in serum from patients with $\mathrm{HCC}$, in serum from healthy individuals or in $10 \%$ FBS were also used to assess TLR2 protein expression by FCM. The cells were collected and washed twice with PBS, stained with $5 \mu \mathrm{l}$ anti-human TLR2-phycoerythrin (PE) antibody (Product \#12-9922-41; 1:1,000; eBioscience $^{\mathrm{TM}}$; Thermo Fisher Scientific, Inc.) at $4^{\circ} \mathrm{C}$ for 30 min away from light. After washing twice with PBS, the cells were collected by low speed centrifugation $(1,000 \mathrm{x} \mathrm{g} ; 5 \mathrm{~min})$ at $4^{\circ} \mathrm{C}$, suspended in $500 \mu \mathrm{l}$ PBS and analyzed by FCM. As a negative control an immunoglobulin G2a-PE antibody was used.

Pam3CSK4activationandplasmidtransfection.TheB76/Huh7 cells were seeded at $2 \times 10^{5}$ cells/well into 6-well dishes and cultured overnight until they reached $70-80 \%$ confluence. The cells were treated with $1 \mu \mathrm{g} / \mu 1$ Pam3CSK4 (Invitrogen; Thermo Fisher Scientific, Inc.) for $72 \mathrm{~h}$ to stimulate the cells. Total cellular protein was extracted for western blotting $24 \mathrm{~h}$ after stimulation. Another set of B76/Huh7 cells were transfected with pcDH-TLR2-GFP-PMV which was designed and constructed by United Innovation of Mengchao Hepatobiliary Technology Key Laboratory of Fujian Province. To create this plasmid, human TLR2 cDNA was PCR amplified and ligated into a Xho1 and BamH digested pcDH-CMV-EF-PURD-GFP vector, and insertion was confirmed by a sequencing company. Additionally, another set of cells was transfected with a GFP-expressing pcDNA-MyD88 plasmid which was provided by another laboratory. The transfected B76/Huh7 
cells were seeded at $2 \times 10^{5}$ cells/well into 6-well dishes and cultured overnight until they reached $70-80 \%$ confluence. Lipofectamine $^{\mathrm{TM}} 3000$ reagent (Invitrogen; Thermo Fisher Scientific, Inc.) was used for transfection of the B76/Huh7 cells according to the manufacturer's protocol. A plasmid DNA (pcDH-TLR2-GFP-PMV, pcDNA-MyD88-GFP or scrambled plasmid) was added to reach a total DNA of $2 \mu \mathrm{g}$ per transfection. The transfected cells were split equally into two 6-well dishes, and cells were incubated for $48 \mathrm{~h}$. In the second 6-well dishes, $24 \mathrm{~h}$ after transfection, the cells were treated with Pam3CSK 4 for $5 \mathrm{~h}$ in 3 wells each. Green fluorescence was emitted after successful transfection. Images were observed and captured using a fluorescence microscope (Axiocam 506; Carl Zeiss) $48 \mathrm{~h}$ after transfection. Images of the cells were composed from white brand images and green fluorescence images.

siRNA transfections. The B76/Huh7 cells were seeded at $2 \times 10^{5}$ cells/well into 6 -well dishes and cultured overnight until they reached $70-80 \%$ confluence. Three groups: TLR2-siRNA-transfected groups; scramble control group; and the blank group were treated in parallel. The sequences for the siRNAs are shown in Table I. Transfections were also performed with Lipofectamine ${ }^{\mathrm{TM}} 3000$ reagent. Transfected cells were incubated for $24 \mathrm{~h}$ and harvested for reverse transcription-quantitative (RT-q)PCR. In regards to the other cells, $48 \mathrm{~h}$ after transfection, these cells were collected for western blotting.

RT-qPCR experiments. Total RNA was extracted from fresh liver HCC tissues and cell lines using Trizol ${ }^{\circledR}$ reagent (Invitrogen; Thermo Fisher Scientific, Inc.). Subsequently, $1 \mu \mathrm{g}$ of total RNA was reverse-transcribed using GoScript ${ }^{\mathrm{TM}}$ Reverse Transcription mix, Oligo(dT) (Promega Corporation, Madison, WI, USA). For qPCR analysis, single-stranded cDNA was synthesized using oligo(dT) primer in a $20 \mu \mathrm{l}$ reaction mixture. The primer sequences used are presented in Table II. The PCR thermocycling conditions were: $95^{\circ} \mathrm{C}$ for $2 \mathrm{~min}$; and $40 \mathrm{cycles}$ of $95^{\circ} \mathrm{C}$ for $10 \mathrm{sec}, 60^{\circ} \mathrm{C}$ for $30 \mathrm{sec}$ and $72^{\circ} \mathrm{C}$ for $30 \mathrm{sec}$. $18 \mathrm{~S}$ rRNA was amplified as a control to normalize expression levels. The level of each mRNA was expressed as a ratio relative to the housekeeper gene using the $2^{-\Delta \Delta \mathrm{Cq}}$ method (13). Experiments were repeated at least three times for each sample to ensure the reproducibility of the results.

Western blot analysis. Cells were harvested and lysed in RIPA buffer (Beyotime Institute of Biotechnology, Haimen, China) for $20 \mathrm{~min}$. The lysate was centrifugated at $17,000 \mathrm{x} \mathrm{g}$ at $4^{\circ} \mathrm{C}$ for $30 \mathrm{~min}$ and protein concentration was determined using a bicinchoninic acid assay. Cell lysates were resolved using a $12 \%$ gel using SDS-PAGE, and transferred to a PVDF membrane (EMD Millipore, Billerica, MA, USA). Membranes were blocked in $5 \%$ non-fat milk and then blots were probed with antibodies against TLR2 (cat. no. 12276; dilution 1:1,000; Cell Signaling Technology, Inc., Danvers, MA, USA), MyD88 (cat. no. 50010; dilution 1:1,000; Cell Signaling Technology), NF- $\kappa$ B (cat. no. 8242; dilution 1:1,000; Cell Signaling Technology) or GAPDH (cat. no. sc-47724; dilution 1:8,000; Santa Cruz Biotechnology, Inc.) overnight at $4^{\circ} \mathrm{C}$. GAPDH

Table I. Primer pairs used for the siRNA sequences.

siRNA name Sequences (5'-3')

TLR2-homo-1375 F

TLR2-homo-1375 R

TLR2-homo-1648 F

TLR2-homo-1648 R

TLR2-homo-950 R

TLR2-homo-950 F

MYD88-homo-987 F

MYD88-homo-987 R

MYD88-homo-760 F

MYD88-homo-760 R

MYD88-homo-316 F

MYD88-homo-316 R

Negative control $\mathrm{F}$

Negative control $\mathrm{R}$

NCFAM F

NCFAM R

GAPDH F

GAPDH R

GCCCUCUCUACAAACUUUATT

UAAAGUUUGUAGAGAGGGCTT

GCAACUCAAAGAACUUUAUTT

AUAAAGUUCUUUGAGUUGCTT

GGUGAAACAAAUUCAUUGATT

UCAAUGAAUUUGUUUCACCTT CCCAUCAGAAGCGACUGAUTT

AUCAGUCGCUUCUGAUGGGTT

GGCAACUGGAACAGACAAATT

UUUGUCUGUUCCAGUUGCCTT

GCCUGUCUCUGUUCUUGAATT

UUCAAGAACAGAGACAGGCTT

GAGGCCAAGCCCTGGTATG

CGGGCCGATTGATCTCAGC

UUCUCCGAACGUGUCACGUTT

ACGUGACACGUUCGGAGAATT

UGACCUCAACUACAUGGUUTT

AACCAUGUAGUUGAGGUCATT

F, forward; R, reverse. TLR2, Toll-like receptor 2; MyD88, myeloid differentiation factor 88 .

Table II. Primer pairs used for TLR2 pathway molecules and downstream factors.

Oligo name Primer sequences (5'-3')

TLR2 F

TLR2 R

MYD88 F

MYD88 R

$\mathrm{NF}-\kappa \mathrm{B} F$

NF- $\kappa$ B R

$18 \mathrm{~S} \mathrm{~F}$

$18 \mathrm{~S} R$

IL-6 F

IL-6 R

IL-8 F

IL-8 R

TNF- $\alpha$ F

TNF- $\alpha$ R

IFN- $\beta$ F

IFN- $\beta$ R

F, forward; R, reverse. TLR2, Toll-like receptor 2; MyD88, myeloid differentiation factor 88 ; IL, interleukin; TNF- $\alpha$, tumor necrosis factor- $\alpha$; INF- $\beta$, interferon- $\beta$.

(Santa Cruz Biotechnology, Inc., Dallas, TX, USA) was used as a loading control with the same operation. After washing the membrane three times with PBST for $10 \mathrm{~min}$ each wash, the membrane was incubated with the appropriate horseradish 

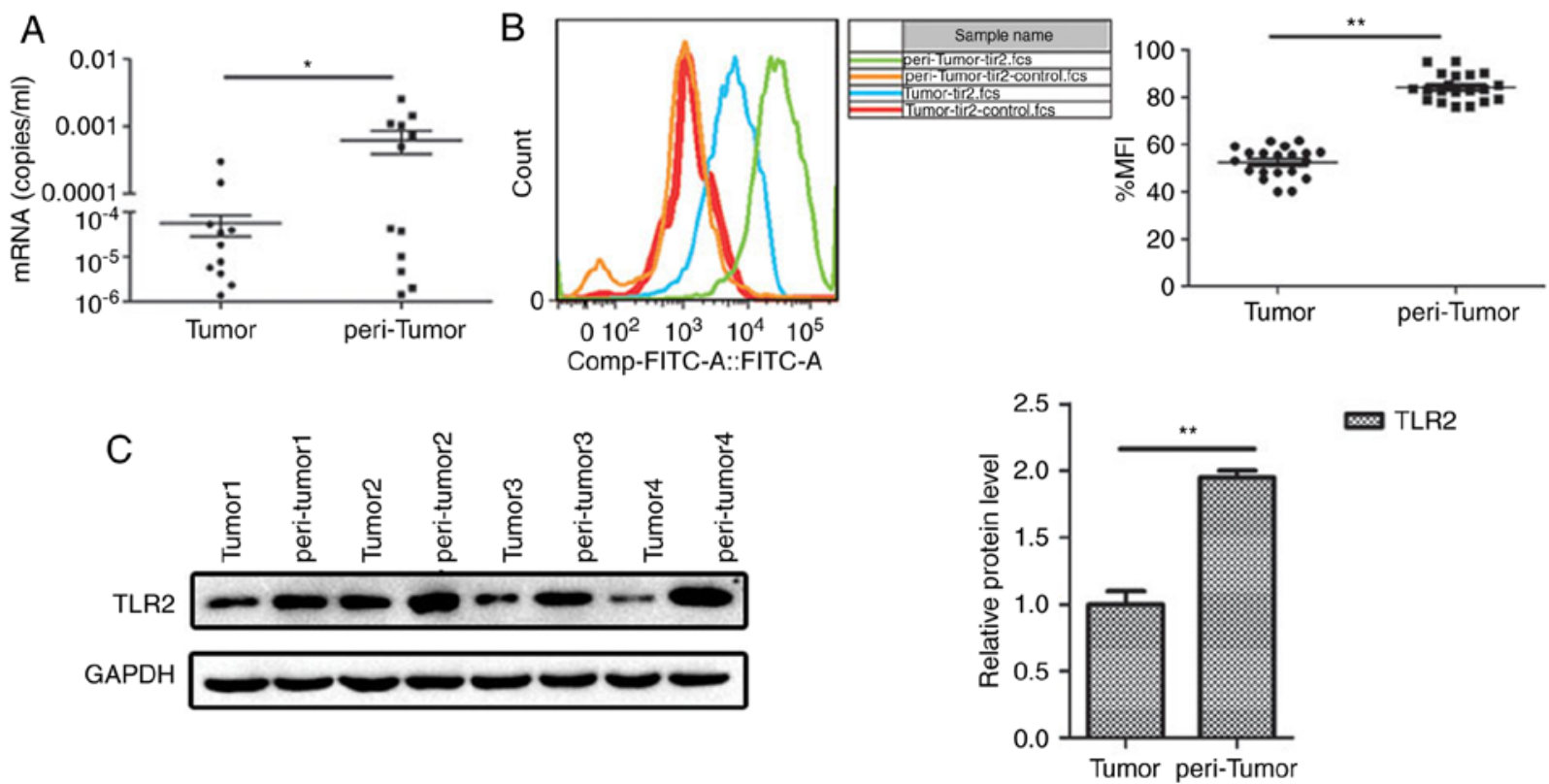

Figure 1. TLR2 expression in tumor and the peritumoral tissues from HCC patients. (A) Quantitative PCR, (B) flow cytometry and (C) western blot analysis of TLR2 expression. ${ }^{*} \mathrm{P}<0.05,{ }^{* *} \mathrm{P}<0.01$. TLR2, Toll-like receptor 2; HCC, hepatocellular carcinoma.

peroxidase-conjugated secondary antibody (cat. no. sc-2357; 1:5,000; Santa Cruz Biotechnology, Inc. or cat. no. sc-516102; dilution 1:5,000; Santa Cruz Biotechnology, Inc.). After washing three times with PBST for 10 min each wash, the protein bands were visualized using enhanced chemiluminescence. Densitometry analysis (Bio-Rad Laboratories) was performed using GAPDH as a control.

Cell proliferation assay and ELISA. Proliferation of B76/Huh7 cells was measured using Cell Counting Kit-8 (CCK-8) assay (Phygene, Shanghai, China) at 0, 24, 48 and $72 \mathrm{~h}$ following treatment with $5 \mu \mathrm{g} / \mathrm{ml}$ TLR2 agonist Pam3CSK4. Cells were cultured in 96-well cell plates (1.5×10\%/well; 6 wells per condition) overnight, after which the cells were transfected or treated as described above. After transfection, a sample of the transfected cells was collected as the $0 \mathrm{~h}$ sample, while the other cells were further cultured for 24,48 or $72 \mathrm{~h}$. At the end of each treatment period, CCK- 8 reagent was added to the culture medium at a concentration of $5 \mathrm{mg} / \mathrm{ml}$ and incubated for $4 \mathrm{~h}$ at $37^{\circ} \mathrm{C}$. The supernatant was then removed, and cells were mixed with $100 \mu \mathrm{l} /$ well CCK-8 solution. The absorption was measured using a microplate reader (Spectra Max M5; Molecular Devices, LLC, Sunnyvale, CA, USA) at $450 \mathrm{~nm}$. The supernatant was collected, and ELISA kits were used to measure IL- 6 , IL- 8 , IFN- $\beta$, TNF- $\alpha$ production (R\&D Systems China Co., Ltd., Shanghai, China) 24, 48 and $72 \mathrm{~h}$ after transfection.

Flow cytometry for determining apoptosis. A total of $48 \mathrm{~h}$ after transfection, the cells were trypsinized, collected, washed twice with cold PBS and $1 \times 10^{6}$ cells were resuspended in $100 \mu \mathrm{l}$ of Annexin V binding buffer. A total of $5 \mu \mathrm{l} \mathrm{APC}$ Annexin V and $5 \mu 1$ 7-AAD (BD Biosciences) was added into the cell suspension. The cells were gently vortexed and incubated for $15 \mathrm{~min}$ at room temperature in the dark. A total of $400 \mu \mathrm{l}$ binding buffer was added to each tube and analyzed by flow cytometry.

Statistical analysis. Statistical analysis was performed using GraphPad 6.0 (GraphPad Software Inc, La Jolla, CA, USA). Data from at least three experiments are expressed as mean value \pm standard deviation and were interpreted using one-way ANOVA followed by Bonferroni or Dunnett test where relevant. All comparisons were determined using a repeated measures one-way ANOVA between the experimental group and the control group. $\mathrm{P}<0.05$ was considered to indicate a statistically significant difference.

\section{Results}

TLR2 expression is significantly downregulated in liver tumor tissue of patients with HCC. To examine the role of TLR2 in HCC progression, semi-quantitative RT-PCR and FCM were used. The results showed that TLR 2 expression in the peritumoral tissues was significantly higher compared with that noted in the tumor tissues (Fig. 1A and B). The protein expression level of TLR2 was determined using western blotting, and similar to the PCR results, protein expression of TLR2 was significantly higher in the peritumoral tissue compared with that noted in the tumor tissue (Fig. 1C). Our complementary study of 141 samples showed the expression levels of TLR 2 in the tissues of liver and no differences were found for different stage and prognosis (Table SI).

TLR2 signaling pathway and HCC proliferation. To distinguish whether the serum of patients with HCC was able to interfere with the TLR2 signaling pathway in HCC cells through the activation of Pam3CSK4, the TLR2 expression in B76/Huh7 cells was detected by FCM after $48 \mathrm{~h}$ of culturing with the serum of $\mathrm{HCC}$ patients $(\mathrm{Ca})$, with the serum of normal healthy individuals (Normal) or FBS. 
A

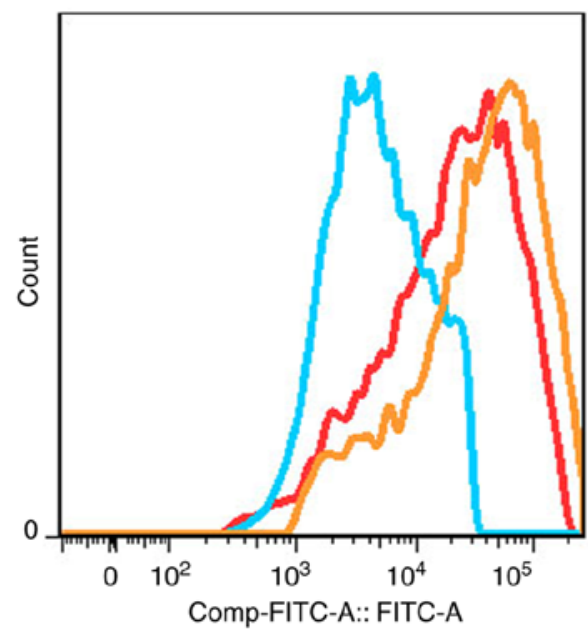

$\mathrm{B}$
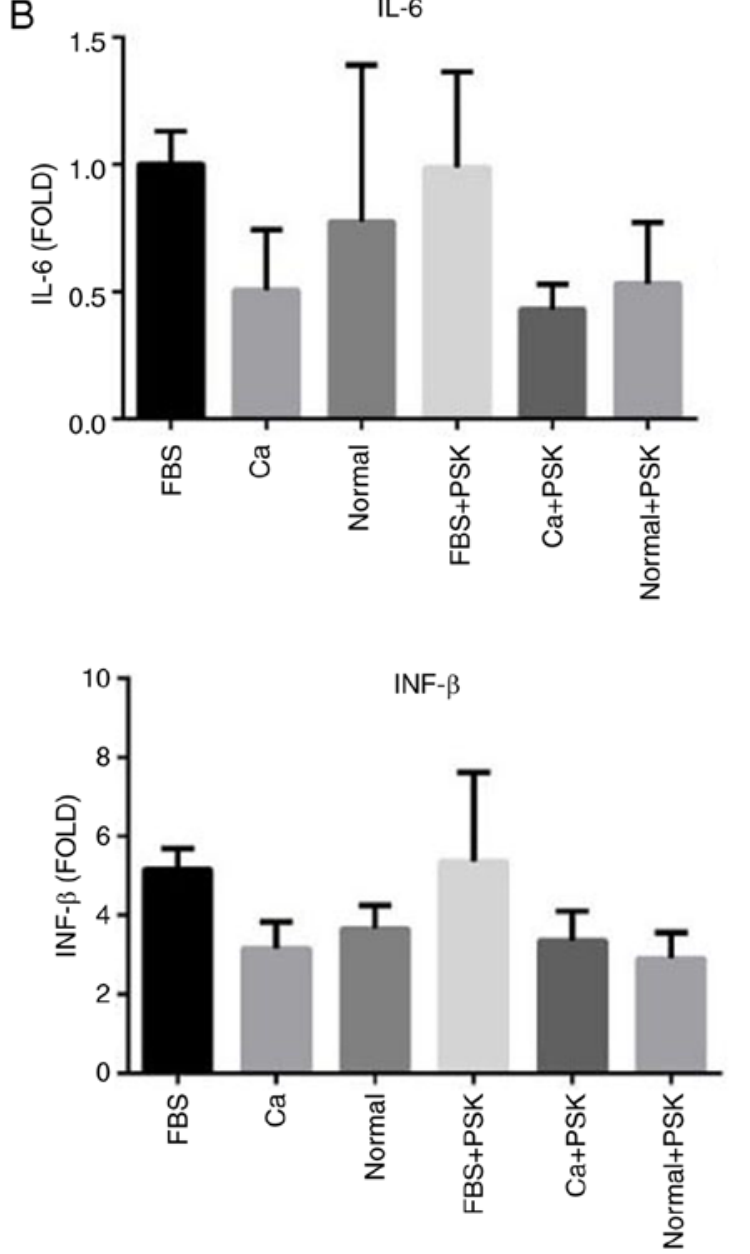
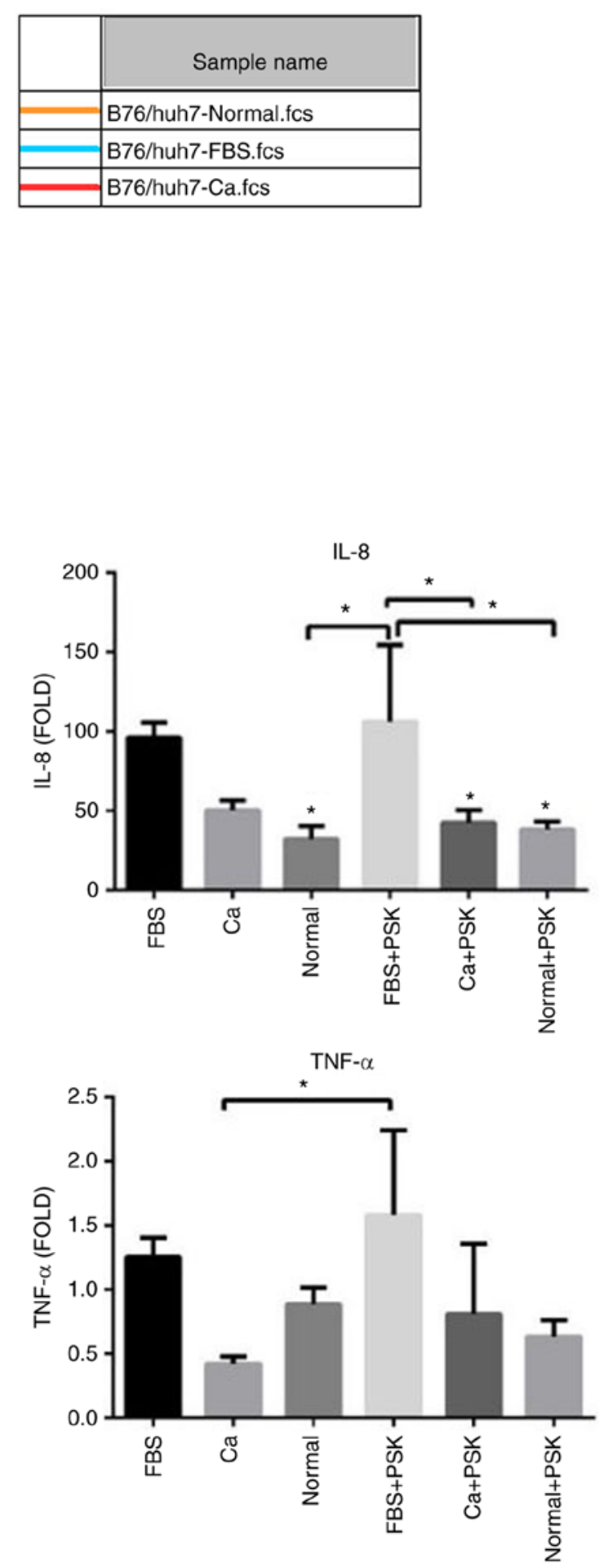

Figure 2. (A) TLR2 expression in the B76/Huh7 cell line at $48 \mathrm{~h}$ following culture with the serum of patients with $\mathrm{HCC}$ (Ca), the serum of healthy individuals (normal) or FBS by flow cytometry. (B) IL-6, IL-8, interferon (INF)- $\beta$ and tumor necrosis factor (TNF)- $\alpha$ in B76/Huh7 cell line $48 \mathrm{~h}$ after culture with the serum of patients with hepatocellular carcinoma, with the serum of healthy individuals or FBS. Reverse transcription-quantitative PCR was performed with the fold change of IL-6 in the cells supplemented with FBS as the positive internal control. The data for the samples are expressed relative to the average value of the control samples \pm standard deviations of the means. " $\mathrm{P}<0.05$, compared with the FBS group. The data were analyze by one-way ANOVA and the Bonferroni (compared with each other) and Dunnett (compared with FBS) post hoc tests were used, respectively. TLR2, Toll-like receptor 2; IL, interleukin; PSK, Pam3CSK4.

The results showed that the expression of TLR2 decreased in the cells treated with serum from HCC patients when compared with cells treated with the serum from healthy individuals (Fig. 2A). Transcription of various inflammatory cytokines such as IL- 8 and TNF- $\alpha$ was altered, as determined by qPCR. Compared with the cells treated with FBS, expression of inflammatory cytokines was decreased in cells treated with serum from patients with $\mathrm{HCC}(\mathrm{Ca})$ and in cells treated with serum from healthy individuals (Normal). Inflammatory cytokine levels of TLR2-mediated 

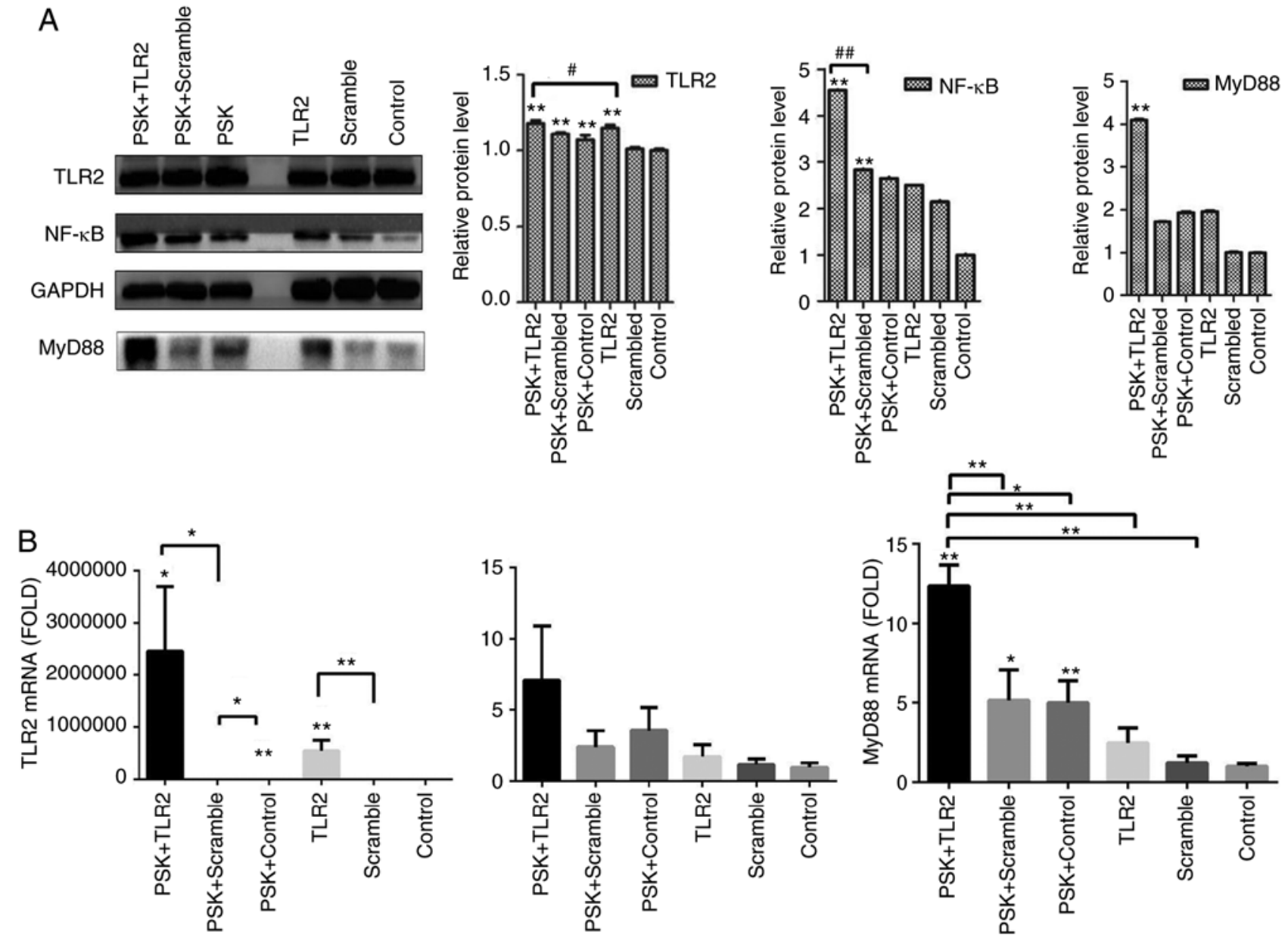

Figure 3. (A) Expression of protein in the B76/Huh7 cells transfected with the TLR2 plasmid (TLR2), scrambled plasmid or control were detected by western blotting and the relative expression levels of protein are presented. The three left lanes are protein extracts from cells stimulated with Pam3CSK4 (PSK) and the three right lanes are protein extracts from unstimulated cells. (B) Relative expression levels of mRNA as detected by qPCR. ${ }^{*} \mathrm{P}<0.05$, ${ }^{* *} \mathrm{P}<0.01 \mathrm{vs}$. control. ${ }^{\#} \mathrm{P}<0.05$, compared with each other. ${ }^{\# \#} \mathrm{P}<0.01$, compared with each other. TLR2, Toll-like receptor 2.

activation of cells treated with the serum of HCC patients and serum from healthy individuals were lower than in the cells treated with FBS especially following the activation of Pam3CSK4 (PSK), confirming efficient inverse feedback (Fig. 2B). This suggests that some component of the serum from patients with HCC interfered with the TLR2 signaling pathway through Pam3CSK4 activation in liver cells and reduced the TLR2-mediated immune inflammation. Yet, this substance remains unknown and further experiments are warranted.

To confirm the findings with TLR2 in vitro, a TLR2 agonist, Pam3CSK4, was used to stimulate B76/Huh7 cells. Following treatment with the agonist, the cells were assayed by qPCR, western blotting and FCM (Fig. S1). The protein expression levels of signaling pathway proteins, including MyD88, IRAK1, TRAF6 and NF- $\mathrm{B}$ were significantly increased $48 \mathrm{~h}$ after stimulation with Pam3CSK4 (Fig. S2A). The relative protein levels of the signaling molecules were also increased (Fig. S2B).

Overexpression of TLR2 and Myd88 combined with treatment with the agonist Pam3CSK4 inhibits the proliferation and accelerates apoptosis. To detect the efficiency of TLR2-overexpression plasmid and whether the pathway was activated by TLR2 agonist, B76/Huh7 cells were divided into six groups: TLR2-overexpression plasmid group; scramble group and the blank group with or without stimulation with Pam3CSK4. The results demonstrated that the expression of molecules in the TLR2 signaling pathway, such as TLR2 and MyD88 in the TLR2-overexpression groups were significantly higher than in the scramble groups compared with the control groups, particularly when stimulated with Pam3CSK4, both at the protein level (Fig. 3A) and gene level $48 \mathrm{~h}$ after transfection (Fig. 3B). Images of B76/Huh7 cells transfected with the plasmids were obtained using a fluorescence microscope at the same time (Fig. S3).

To detect the efficiency of MyD88-overexpression plasmid, B76/Huh7 cells were also divided into six groups; MyD88-overexpression plasmid group; scramble group; and the blank group with or without Pam3CSK4 stimulation. In comparison with the scramble groups and the control groups, MyD88-overexpression plasmid group also demonstrated higher expression of TLR2 and MyD88 both at the protein level (Fig. 4A) and gene level (Fig. 4B) $48 \mathrm{~h}$ after transfection, particularly when stimulated with Pam3CSK4. There was no consistent corresponding alterations in the expression of $\mathrm{NF}-\kappa \mathrm{B}$ following transfection with either of the two plasmids (Figs. 3 and 4). Images of transfected cells with the plasmids 

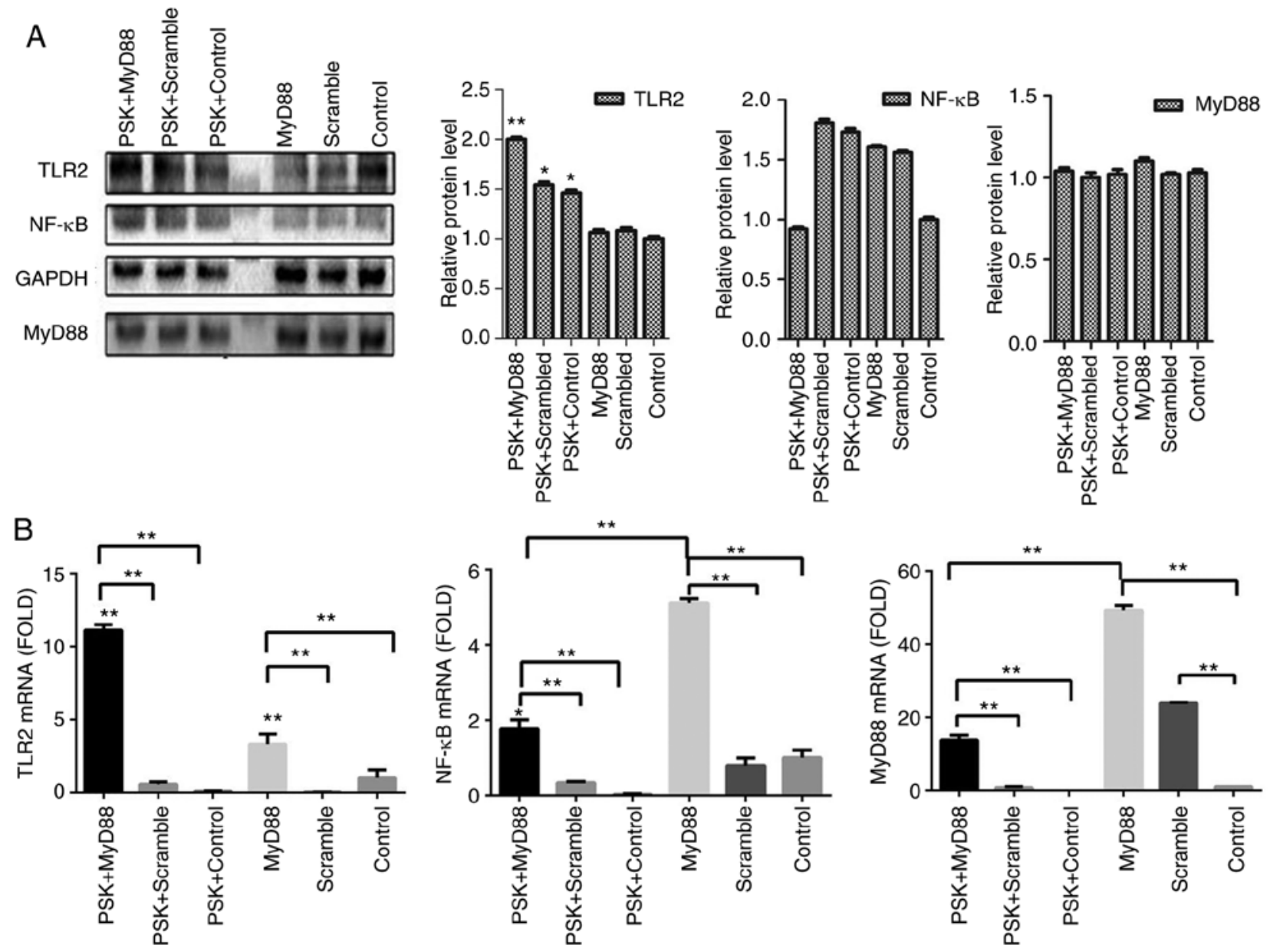

Figure 4. (A) Relative expression of protein in B76/Huh7 cells transfected with the MyD88 plasmid, scrambled plasmid and control as detected by western blotting. The three left lanes in the western blot show expression from cells stimulated with Pam3CSK4 (PSK) and the three right lanes show expression from unstimulated cells. (B) Relative expression levels of mRNA. ${ }^{*} \mathrm{P}<0.05,{ }^{* *} \mathrm{P}<0.01$ vs. the Control. TLR2, Toll-like receptor 2; MyD88, myeloid differentiation factor 88 .

in B76/Huh7 cells were obtained using a fluorescence microscope (Fig. S4).

The functional experiments showed that overexpression of TLR2 and MyD88 significantly inhibited the proliferation of B76/Huh7 cells (Fig. 6A and B) and significantly increased apoptosis of B76/Huh7 cells (Fig. 7A and B).

RNA interference increases proliferation and decreases apoptosis. To detect the efficiency of TLR2-siRNA or MyD88-siRNA, cells were divided into five groups per a target RNA: siRNA1 group, siRNA2 group, siRNA3 group, scramble group and the blank group. The results of the qPCR and western blotting demonstrated that the expression of protein and messenger RNA (mRNA) of TLR2 or MyD88 in the siRNA groups was significantly decreased compared with the blank groups $(\mathrm{P}<0.05)$. It was observed that all six different siRNAs significantly reduced expression of TLR2 and MyD88 at the protein (Fig. 5A) and gene expression level (Fig. 5B). The results also showed that the expression of $\mathrm{NF}-\kappa \mathrm{B}$ did not significantly differ at the gene and protein level. The siRNAs with the largest decrease in the expression levels for both TLR2 and MyD88 were used for the subsequent experiments. Knockdown of TLR2 or MyD88 significantly increased proliferation (Fig. 6C and D) and decreased apoptosis significantly (Fig. 7A and B) in the B76/Huh7 cells.

Inflammatory cytokines serve crucial roles in antitumor activity. To investigate the role of cytokines through the activation of the TLR2 signaling pathway, IL-6, IL-8, TNF- $\alpha$ and IFN- $\beta$ concentrations were assayed in the supernatant of cells using ELISA, 24, 48 and $72 \mathrm{~h}$ after transfection of the TLR2-overexpression-plasmid or MyD88-overexpression-plasmid in B76/Huh7 cell line. The results showed that IL- 6 and TNF- $\alpha$ expression was decreased and IL- 8 and IFN- $\beta$ secretion was increased slowly between 24 and $48 \mathrm{~h}$ in the TLR2-overexpressing cells and following stimulation with Pam3CSK4 in the supernatants of the B76/Huh7 cells. IL-6 and TNF- $\alpha$ secretion was decreased in the MyD88-overexpressing cells and following stimulation with Pam3CSK4 between the 24 and 48 h timepoints in the supernatants of B76/Huh7 cells. IL- 6 and TNF- $\alpha$ secretion was increased in the MyD88-overexpressing cells and Pam3CSK4 stimulated cells between 48 and $72 \mathrm{~h}$. But IL- 8 secretion was increased slowly between 24 and $72 \mathrm{~h}$ in the supernatants of the B76/Huh7 cells and IFN- $\beta$ was decreased slightly in quantitative terms between $24 \mathrm{~h}$ and $72 \mathrm{~h}$ in the supernatants of B76/Huh7 cells (Fig. 8). Next it was determined whether the 

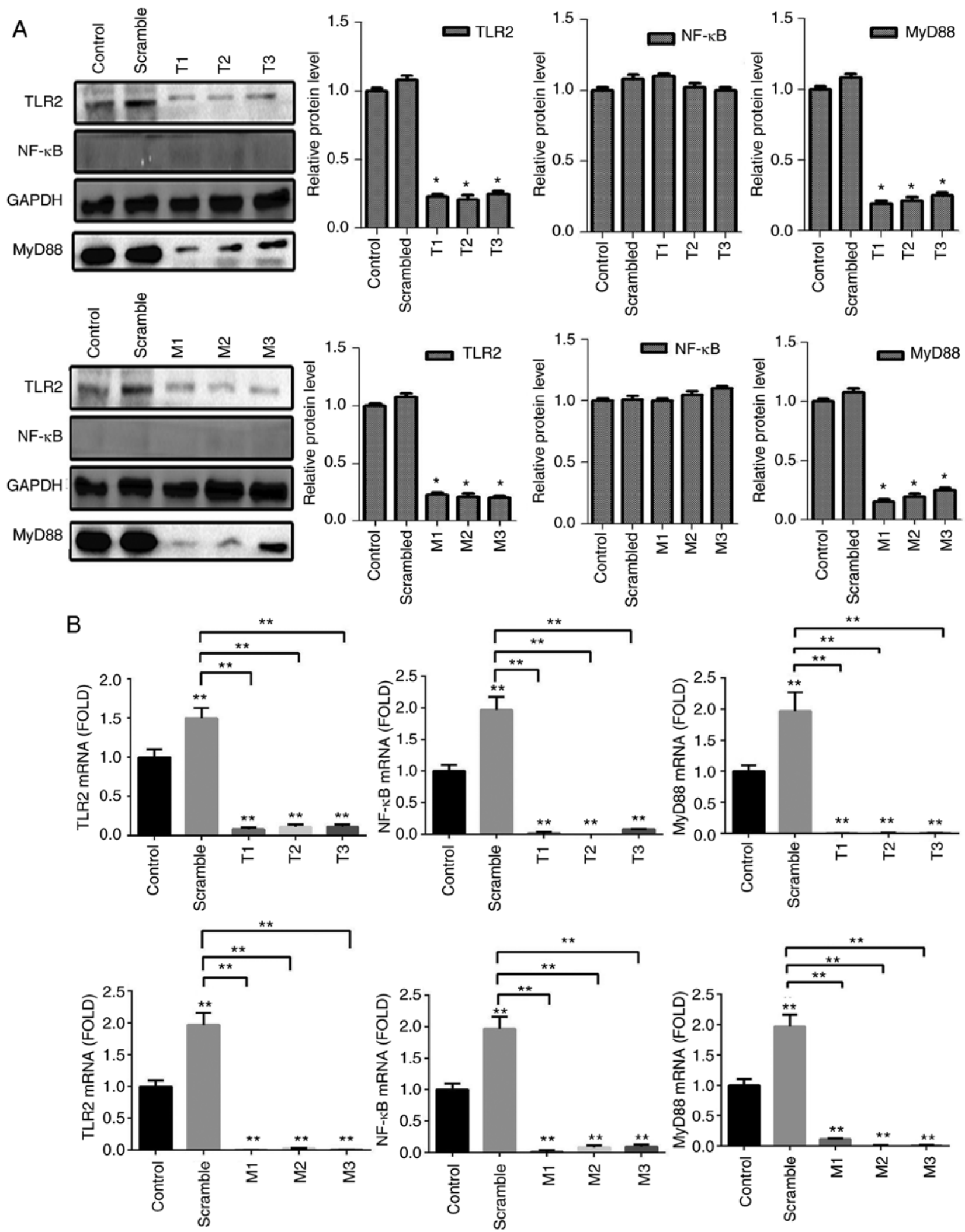

Figure 5. Silencing of the TLR2 signaling pathway by TLR2-siRNA (T1, T2, T3) (upper panels) and MyD88-siRNA (M1, M2, M3) (lower panels) in the B76/Huh7 cells. (A) Protein levels were detected by western blotting. (B) Relative expression levels of mRNA. ${ }^{*} \mathrm{P}<0.05,{ }^{* *} \mathrm{P}<0.01$ vs. the Control. TLR, Toll-like receptor 2; MyD88, myeloid differentiation factor 88.

function of the TLR2 pathway was associated with IL-6, IL-8, TNF- $\alpha$, and IFN- $\beta$ in B76/Huh7 cells lines. The results showed that the proinflammatory cytokines, such as IL- 6 and TNF- $\alpha$ were decreased and anti-inflammatory cytokines, including
IL-8 and IFN- $\beta$ increased when the cells were transfected with the TLR2 plasmid in B76/Huh7 cells. IL-6 and TNF- $\alpha$ secretion was increased between 48 and $72 \mathrm{~h}$ suggesting that additional MyD88 pathways were also stimulated in B76/Huh7 cells. 

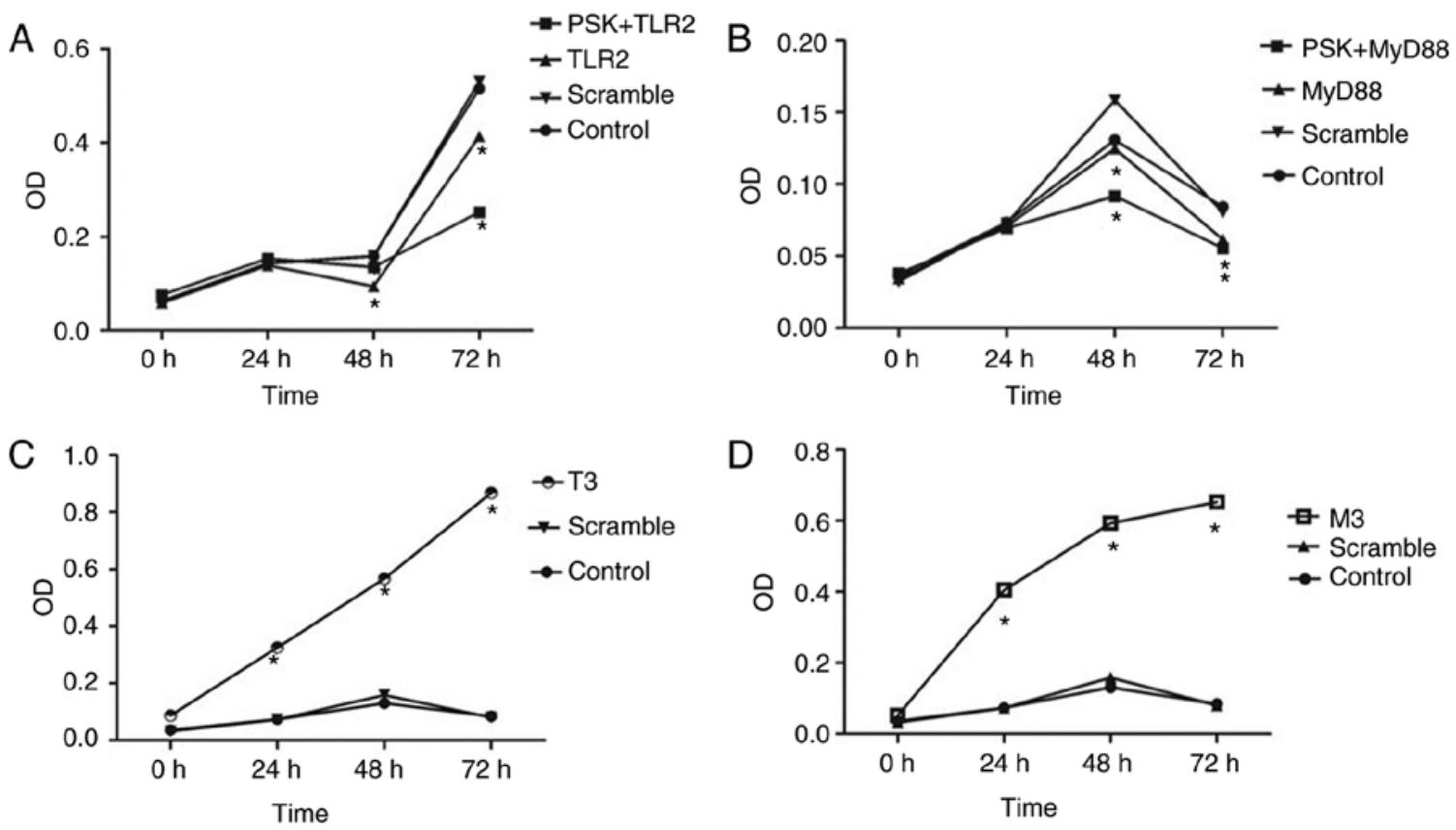

Figure 6. Activation of the TLR2 signaling pathway by overexpression of (A) TLR2 or (B) MyD88 inhibited the proliferation of B76/Huh7 cells. (C and D) Silencing of the TLR2 signaling pathway promoted proliferation of B76/Huh7 cells. ${ }^{*} \mathrm{P}<0.05$ vs. the control. ${ }^{* *}$ The PSK+MyD88 vs. the control and the MyD88 vs. the control respectively. TLR, Toll-like receptor 2; MyD88, myeloid differentiation factor 88.

\section{Discussion}

TLR2 appears to be an essential stress-sensor the absence of which reveals an augmented tendency to accumulate damage to the DNA and reduce cell survival in HCC (5). In the present study, TLR2 expression in HCC, its effect on cellular proliferation, apoptosis as well as secretion of cytokines in B76/Huh7 cell line was evaluated. In HCC tissues, mRNA and protein expression levels of TLR 2 were decreased in tumoral tissues compared with that in the peritumoral tissues. Additionally, the expression levels of TLR2 were significantly increased when TLR2 and/or MyD88 were overexpressed and downregulated when expression of either of these was silenced. Activation of TLR2 through overexpression of proteins involved in the signaling TLR2 pathway decreased proliferation of B76/Huh7 cells. The mRNA and protein expression levels of genes encoded by the plasmids were significantly upregulated in B76/Huh7 cells when stimulated with Pam3CSK4, suggesting that the TLR2 agonist enhanced the expression of the plasmids. However, inhibition of the signaling pathway caused a significant increase in the downstream signaling cascade, thus increasing proliferation in the B76/Huh7 cell lines. Finally, secretion of IL-6 and TNF- $\alpha$ was decreased, whereas secretion of IL-8 and IFN- $\beta$ was increased following transfection with either of the overexpression plasmids in B76/Huh7 cells.

Several animals $(6,7)$ and in vitro $(10,11,14)$ studies have implicated TLR2 in human liver tumors. In wild-type mice with diethylnitrosamine (DEN)-induced HCC, deficiency of TLR2 resulted in the suppression of immune responses to DEN-induced injury, thus serving an important role in liver carcinogenesis and tumor progression (6). TLR1/2 stimulation in mouse LSECs increased $\mathrm{CD}^{+} \mathrm{T}$ cell immunity in vitro (7). A previous demonstrated that the activation of the ASK1/p38 MAPK/NF- $\kappa B$ pathway is critical for both neutralizing reactive oxygen species/endoplasmic reticulum stress and repairing damaged DNA (15). However, studies on the underlying mechanism demonstrating a causal link between TLR2 and tumor proliferation in the liver tumor microenvironment are rare. In the present study, it was demonstrated that TLR2 expression in the HCC tissues was associated with increased expression of molecules involved in the TLR2 signaling pathway. Both TLR2 and MyD88 are important pathway molecules affecting the proliferation and apoptosis of HCC cells $(16,17)$. In theory, we conclude that MyD88 is a more popular signaling pathway molecule because MyD88 is also included in many Toll like receptor signaling systems $(4,7,8,9,11)$ and plays roles in affecting the proliferation and apoptosis of HCC cells (18). Modulation of TLR2 was more pronounced when TLR2 was overexpressed compared with MyD88 in the cell proliferation or apoptosis assays and this may be because many TLRs potently activate the NF- $\kappa B$ pathway which subsequently alters MyD88 molecules. The TLR2 agonist, Pam3CSK4, was used to activate the TLR2 signaling pathway. Pam3CSK4 has been demonstrated to alter the expression of pathway molecules and inhibit tumor growth in wild-type mice (11). TLR2 is primarily expressed on traditional immune cells such as monocytes (19), macrophages (20), dendritic cells (21), B cells (22) and T cells (23). Recently, studies have demonstrated the effect of the knockdown of the TLR2 gene in various hepatoma cell lines $(10,24)$. Huang et al indicated that the knock down of TLR2 in BEL-7402 cells could resist immune cell attack and evade immune surveillance (24). Furthermore, downstream expression of IL-6 was decreased. These results agree with the results of the present study in B76/Huh7 cells were silencing of TLR2 could promote tumor proliferation and inhibit apoptosis. Shi et al (10) found that proliferation, invasion and migration in the siRNA group was decreased compared with the control, and the apoptotic ratio was increased in TLR2-siRNA transfected 
A
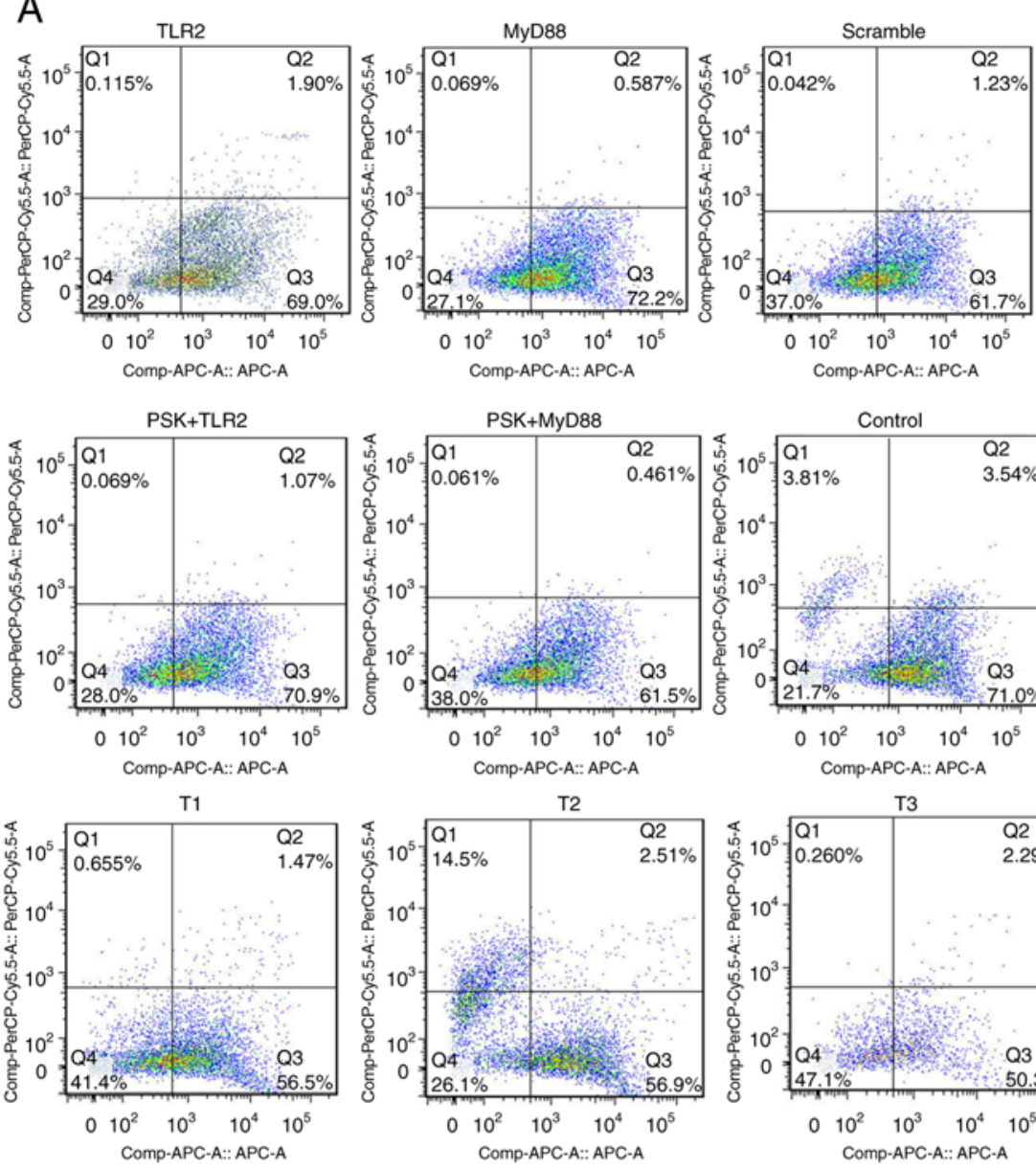

M1

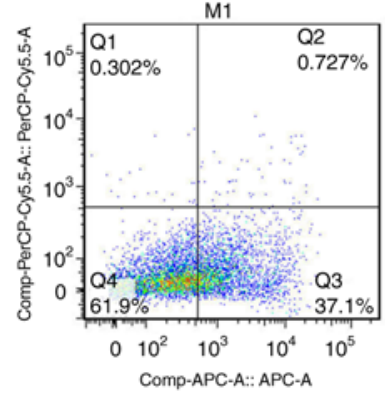

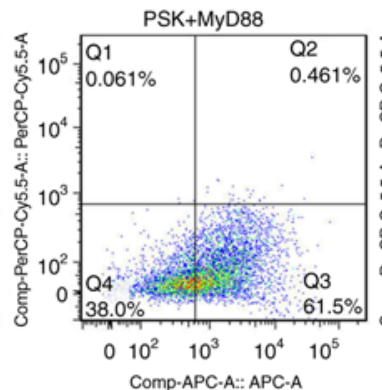

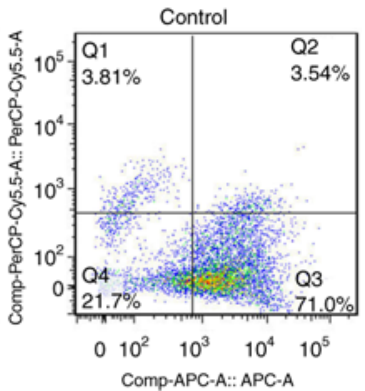

T2
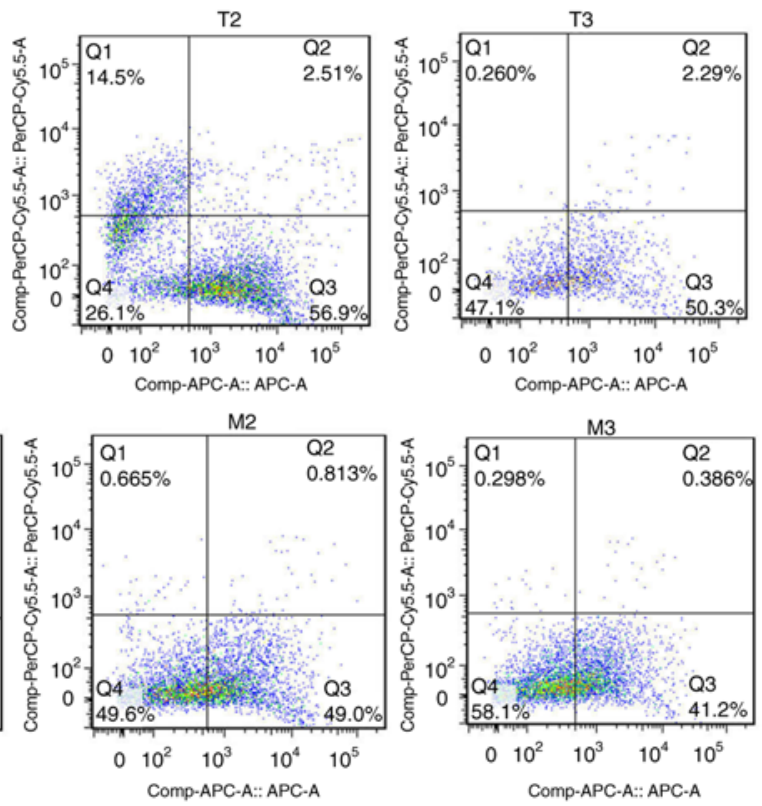

B

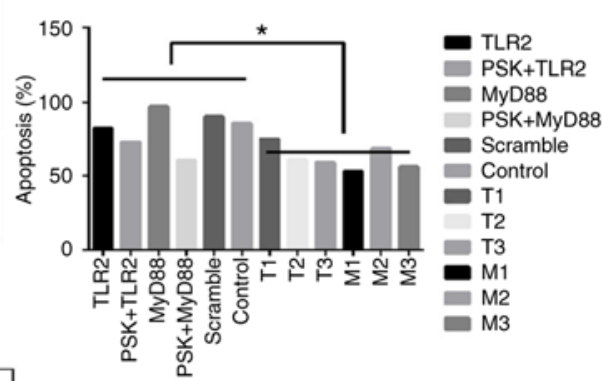

Figure 7. Apoptosis of B76/Huh7 cells as detected by flow cytometry. The apoptotic rate was detected $48 \mathrm{~h}$ after treatment. Cells in the lower and upper right quadrants were considered as early and late apoptosis, respectively. (A) Activation of the TLR2 signaling pathway increased apoptosis in B76/Huh7 cells. Silencing of the TLR2 signaling pathway by silencing of TLR2 or MyD88 inhibited apoptosis in B76/Huh7 cells (B) A compare of apoptotic rate in activation or silenceing of TLR2 signaling pathway in macroscopic. ${ }^{*} \mathrm{P}<0.05$. TLR, Toll-like receptor 2 ; MyD88, myeloid differentiation factor 88 .

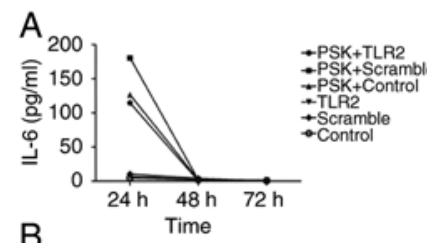

$\mathrm{B}$

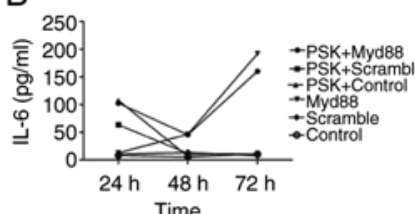

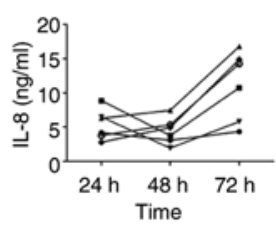

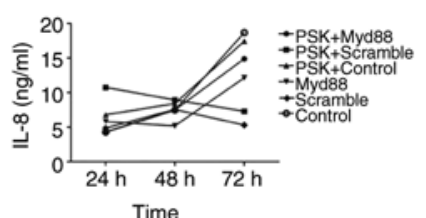

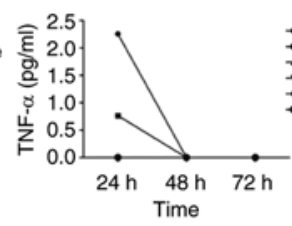
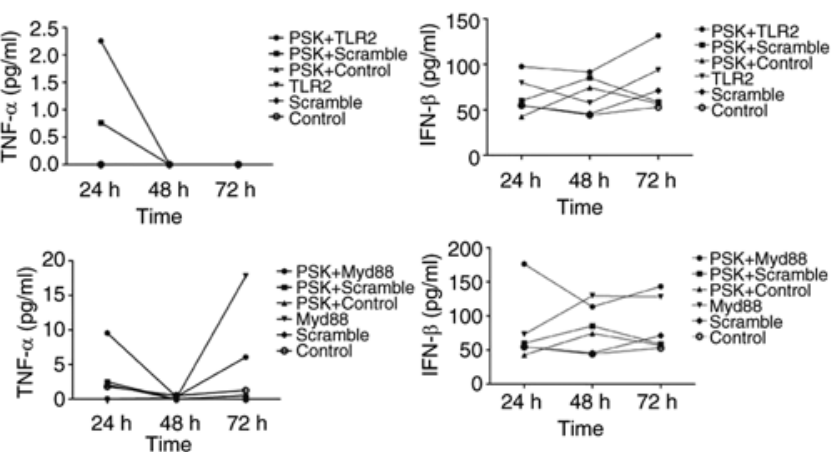

Figure 8. Activation of TLR2 signaling pathway molecules following TLR2 (A) or MyD88 (B) overexpression with PSK or without PSK treatment altered the downstream factors of interleukin (IL)-6, tumor necrosis factor (TNF)- $\alpha$, IL-8 and interferon (INF)- $\beta$ in B76/Huh7 cells after 24,48 and $72 \mathrm{~h}$ of culture, respectively. PSK, Pam3CSK4; TLR, Toll-like receptor 2; MyD88, myeloid differentiation factor 88. 
HepG2 cells treated with recombinant high mobility group box 1 protein. These results contradict the results of the present study where silencing of TLR2 and MyD88 in B76/Huh7 cells increased proliferation and inhibited apoptosis. The results suggest that modulation of the TLR2 pathway may differ in different cell lines. There are many other TLR2 agonists except for Pam3CSK4 (25). Regulation of TLR2 expression may be achieved through the NF- $\mathrm{BB}$ signaling pathway, which is one of the major sensors of cytokine secretion (26). Cytokines are important mediators of cancer-promoting inflammation (27). IL-6 and TNF- $\alpha$ are proinflammatory mediators in the chronically injured liver and contribute to the development of HCC $(26,28)$. In the present study, secretion of IL-6 and TNF- $\alpha$ was decreased following transfection with the overexpression plasmids. These cytokines target hepatoma cells, such as primary immune cells, and reduce their proliferation (29). IL-8 induced apoptosis of HCC and IFN- $\beta$ attenuated hepatocellular carcinoma progression through inhibition of the AKT/FOXO3a pathway $(30,31)$. IL-8 and IFN- $\beta$ anti-inflammatory cytokines were increased and had the opposite effect on hepatoma cells following transfection with the overexpression plasmids. Many cytokines in the serum of HCC patients were investigated, and the volume of tumor was shown to be associated with cytokines (32-35). These cytokines may serve an important pro- or anti-tumorigenic role which may be altered by the TLR2 pathway, thus modulating proliferation (35). IL-6 and TNF- $\alpha$ secretion was increased between 48 and $72 \mathrm{~h}$ after transfection with pcDNA-MYD88-GFP, suggesting that other MyD88 pathways may be stimulated in B76/Huh7 cells (36-38). Yet, we concluded that the content of cytokines was different in serum of HCC patients and normal individuals. Differences are also defined in regards to other factors, such as the ethnicity of the study population and the disease stage $(39,27)$. Additional experimentation is required to support this hypothesis.

In summary, the downregulation of TLR 2 in the HCC tissues, otherwise the increasing expression of TLR2 was associated with a recovery in HCC progression. The liver cells were also considered as immune cells and associated with signaling network. The TLR2 signaling pathway is considered as a potential antiviral mechanism in the hepatitis B infection of hepatic cell lines (40). The TLR2 signaling pathway in immune cells is also a subject of increasing study, and it is hypothesized to trigger the escape of immune-mediated tumor cells and thus tumor progression (15). The results of the present study contributed to understanding the role of the TLR2 pathway in HCC and attempted to partly explain the carcinogenicity and immunogenicity of TLR2 in the liver. But experiments in vivo were not conducted in the present study and further studies of TLR2 in vivo in regards to HCC are warranted.

TLR2 is an important Toll like receptor family members which inhibits the development of HCC. The use of systemically delivered TLR 2 to activate the TLR 2 signaling pathway may provide a novel treatment for the prevention of cancer progression, potentially leading to improved prospects of survival.

\section{Acknowledgements}

The author thank Dr MenJiLu and Dr Yingchao Wang for providing technical support.

\section{Funding}

This study was supported by Fuzhou Science and Technology Plan Projects (grant no. 2015-S-143-12); the Health and Family Planning Commission Project of Fujian Province (grant no. 2015-CXB-30); the National Nature Science Foundation of China (grant no. 81670532); the Provincial Natural Science Foundation of Fujian (grant no. 2015J01361); and the Fuzhou Infectious Diseases Medical Center (grant no. 003040008).

\section{Availability of data and materials}

The datasets used during the present study are available from the corresponding author upon reasonable request.

\section{Authors' contributions}

$\mathrm{YC}$ and $\mathrm{ZH}$ conceived and designed the experiments. $\mathrm{YC}$ performed the experiments. $\mathrm{YC}, \mathrm{ZH}$ and $\mathrm{XC}$ collected and analyzed the data. YC and HY interpreted the findings and wrote the manuscript. All authors read and approved the manuscript and agree to be accountable for all aspects of the research in ensuring that the accuracy or integrity of any part of the work are appropriately investigated and resolved.

\section{Ethics approval and consent to participate}

The study was approved by the Ethics Committee of the Mengchao Hepatobiliary Hospital of Fujian Medical University (study license no. 2016-007-01). Informed consent was obtained from all patients and healthy recruits.

\section{Patient consent for publication}

Not applicable.

\section{Competing interests}

The authors declare no potential competing interests.

\section{References}

1. El-Serag HB: Hepatocellular carcinoma. N Engl J Med 365: 1118-1127, 2011.

2. Chen WQ, Zheng RS, Zhang SW, Li N, Zhao P, Li GL, Wu LY and $\mathrm{He} \mathrm{J}$ : Report of incidence and mortality in china cancer registries, 2008. Chin J Cancer Res 24: 171-180, 2012.

3. Bieghs V and Trautwein C: The innate immune response during liver inflammation and metabolic disease. Trends Immunol 34: 446-452, 2013.

4. Nolan JP: Endotoxin, reticuloendothelial function, and liver injury. Hepatology 1: 458-465, 1981.

5. Jorge André Gomes Lopes, Marta Borges-Canha and PedroPimentel-Nunes: Innate immunity and hepatocarcinoma: Can toll-like receptors open the door to oncogenesis? World J Hepatol 8: 162-182, 2016.

6. Oliveira-Nascimento L, Massari P and Wetzler LM: The role of TLR2 in infection and immunity. Front Immunol 3: 79, 2012.

7. Lin H, Yan J, Wang Z, Hua F, Yu J, Sun W, Li K, Liu H, Yang H, Lv Q, et al: Loss of immunity-supported senescence enhances susceptibility to hepatocellular carcinogenesis and progression in toll-like receptor 2-deficient mice. Hepatology 57: 171-182, 2013.

8. Liu J, Jiang M, Ma Z, Dietze KK, Zelinskyy G, Yang D, Dittmer U, Schlaak JF, Roggendorf M and Lu M: TLR1/2 ligand-stimulated mouse liver endothelial cells secrete IL-12 and trigger CD8 ${ }^{+}$ $\mathrm{T}$ cell immunity in vitro. J Immunol 191: 6178-6190, 2013. 
9. Soares JB, Pimentel-Nunes P, Afonso L, Rolanda C, Lopes P, Roncon-Albuquerque R Jr, Gonçalves N, Boal-Carvalho I, Pardal F, Lopes S, et al: Increased hepatic expression of TLR2 and TLR4 in the hepatic inflammation-fibrosis-carcinoma sequence. Innate Immun 18: 700-708, 2012.

10. Shi W, Su L, Li Q, Sun L, Lv J, Li J and Cheng B: Suppression of toll-like receptor 2 expression inhibits the bioactivity of human hepatocellular carcinoma. Spring 35: 9627-9637, 2014.

11. Li S, Sun R, Chen Y, Wei H and Tian Z: TLR2 limits development of hepatocellular carcinoma by reducing IL18-mediated immunosuppression. Cancer Res 75: 986-995, 2015.

12. Llovet JM, Brú C and Bruix J: Prognosis of hepatocellular carcinoma: The BCLC staging classification. Semin Liver Dis 19 : 329-338, 1999.

13. Livak KJ and Schmittgen TD: Analysis of relative gene expression data using real-time quantitative PCR and the 2(-Delta Delta C(T)) method. Methods 25: 402-408, 2001.

14. Liu X, Gong J and Xu B: miR-143 down-regulates TLR2 expression in hepatoma cells and inhibits hepatoma cell proliferation and invasion. Int J Clin Exp Pathol 8: 12738-12747, 2015.

15. Kennedy NJ, Cellurale C and Davis RJ: A radical role for p38 MAPK in tumor initiation. Cancer Cell 11: 101-103, 2007.

16. Testro AG and Visvanathan K: Toll-like receptors and their role in gastrointestinal disease. J Gastroenterol Hepatol 24: 943-954, 2009.

17. Karin M and Greten FR: NF-kappaB: Linking inflammation and immunity to cancer development and progression. Nat Rev Immunol 5: 749-759, 2005

18. French SW, Oliva J, French BA, Li J and Bardag-Gorce F: Alcohol, nutrition and liver cancer: Role of toll-like receptor signaling. World J Gastroenterol 16: 1344-1348, 2010.

19. Huang Z, Ge J, Pang J, Liu H, Chen J, Liao B, Huang X, Zuo D, Sun J, Lu M, et al: Aberrant expression and dysfunction of TLR2 and its soluble form in chronic HBV infection and its regulation by antiviral therapy. Antiviral Res 118: 10-19, 2015.

20. Leiguez E, Giannotti KC, Moreira V, Matsubara $\mathrm{MH}$ Gutiérrez JM, Lomonte B, Rodríguez JP, Balsinde J and Teixeira C: Critical role of TLR2 and MyD88 for functional response of macrophages to a group IIA-secreted phospholipase A2 from snake venom. PLoS One 9: e93741, 2014.

21. Shen KY, Song YC, Chen IH, Leng CH, Chen HW, Li HJ, Chong P and Liu SJ: Molecular mechanisms of TLR2-mediated antigen cross-presentation in dendritic cells. J Immunol 192 4233-4241, 2014

22. Bhowmick R, Pore D and Chakrabarti MK: Outer membrane protein A (OmpA) of Shigella flexneri 2a induces TLR2-mediated activation of B cells: Involvement of protein tyrosine kinase, ERK and NF- $\kappa$ B. PLoS One 9: e109107, 2014.

23. Derkow K, Krüger C, Dembny P and Lehnardt S: Microglia induce neurotoxic IL-17+ $\gamma \delta$ T cells dependent on TLR2, TLR4 and TLR9 activation. PLoS One 10: e0135898, 2015.

24. Huang Y, Cai B, Xu M, Qiu Z, Tao Y, Zhang Y, Wang J, Xu Y, Zhou Y, Yang J, et al: Gene silencing of toll-like receptor 2 inhibits proliferation of human liver cancer cells and secretion of inflammatory cytokines. PLoS One 7: e38890, 2012.

25. Landais I, Pelton C, Streblow D, DeFilippis V, McWeeney S and Nelson JA: Human cytomegalovirus miR-UL112-3p targets TLR2 and modulates the TLR2/IRAK1/NFKB signaling pathway. PLoS Pathog 11: e1004881, 2015.
26. Seki E and Schwabe RF: Hepatic inflammation and fibrosis: Functional links and key pathways. Hepatology 61: 1066-1079, 2015.

27. Koca YS, Bulbul M and Barut I: The diagnostic roles of cytokines in hepatobiliary cancers. Biomed Res Int 2017: 2979307, 2017.

28. Heikkilä K, Ebrahim S and Lawlor DA: Systematic review of the association between circulating interleukin-6 (IL-6) and cancer. Eur J Cancer 44: 937-945, 2008.

29. Kuraishy A, Karin M and Grivennikov SI: Tumor promotion via injury- and death-induced inflammation. Immunity 35: 467-477, 2011.

30. Choi SH, Park JY, Kang W, Kim SU, Kim Y, Ahn SH, Ro SW and Han KH: Knockdown of HIF-1 $\alpha$ and IL-8 induced apoptosis of hepatocellular carcinoma triggers apoptosis of vascular endothelial cells. Apoptosis 21: 85-95, 2016.

31. Xie C, Xie DY, Lin BL, Zhang GL, Wang PP, Peng L and Gao ZL: Interferon- $\beta$ gene-modified human bone marrow mesenchymal stem cells attenuate hepatocellular carcinoma through inhibiting AKT/FOXO3a pathway. Br J Cancer 109: 1198-1205, 2013.

32. Taub R: Hepatoprotection via the IL-6/Stat3 pathway. J Clin Invest 112: 978-980, 2003.

33. Pikarsky E, Porat RM, Stein I, Abramovitch R, Amit S, Kasem S, Gutkovich-Pyest E, Urieli-Shoval S, Galun E and Ben-Neriah Y: NF-kappaB functions as a tumour promoter in inflammation-associated cancer. Nature 431: 461-466, 2004.

34. Haybaeck J, Zeller N, Wolf MJ, Weber A, Wagner U, Kurrer MO, Bremer J, Iezzi G, Graf R, Clavien PA, et al: A lymphotoxin-driven pathway to hepatocellular carcinoma. Cancer Cell 16: 295-308, 2009.

35. Xiao P, Long X, Zhang L, Ye Y, Guo J, Liu P, Zhang R, Ning J, $\mathrm{Yu}$ W, Wei F and Yu J: Neurotensin/IL-8 pathway orchestrates local inflammatory response and tumor invasion by inducing M2 polarization of tumor-associated macrophages and epithelial-mesenchymal transition of hepatocellular carcinoma cells. OncoImmunology 7: e1440166, 2018.

36. Dapito DH, Mencin A, Gwak GY, Pradere JP, Jang MK, Mederacke I, Caviglia JM, Khiabanian H, Adeyemi A, Bataller R, et al: Promotion of hepatocellular carcinoma by the intestinal microbiota and TLR4. Cancer Cell 21: 504-516, 2012.

37. Takeda K and Akira S: Microbial recognition by toll-like receptors. J Dermatol Sci 34: 73-82, 2004.

38. Seki E and Brenner DA: Toll-like receptors and adaptor molecules in liver disease: Update. Hepatology 48: 322-335, 2008.

39. Dondeti MF, El-Maadawy EA and Talaat RM: Hepatitis-related hepatocellular carcinoma: Insights into cytokine gene polymorphisms. World J Gastroenterol 22: 6800-6816, 2016.

40. Zhan R, Han Q, Zhang C, Tian Z and Zhang J: Toll-like receptor 2 (TLR2) and TLR9 play opposing roles in host innate immunity against Salmonella enterica serovar Typhimurium infection. Infect Immun 83: 1641-1649, 2015.

This work is licensed under a Creative Commons Attribution-NonCommercial-NoDerivatives 4.0 International (CC BY-NC-ND 4.0) License. 